\title{
Facile Low-temperature Chemical Synthesis and Characterization of a Manganese Oxide/multi-walled Carbon Nanotube Composite for Supercapacitor Applications
}

\author{
Kihun Jang, ${ }^{\dagger}$ Sung-won Lee, ${ }^{\dagger}$ Seongil Yu, ${ }^{\dagger}$ Rahul R. Salunkhe, ${ }^{\S}$ Ildoo Chung, ${ }^{\ddagger}$ Sungmin Choi, ${ }^{\#, *}$ and Heejoon Ahn ${ }^{\dagger, \S, *}$ \\ ${ }^{\dagger}$ Department of Organic and Nano Engineering, Hanyang University, Seoul 133-791, Korea. *E-mail: ahn@hanyang.ac.kr \\ \$Department of Polymer Science and Engineering, Pusan National University, Busan 609-735, Korea \\ §Institute of Nano Science and Technology, Hanyang University, Seoul 133-791, Korea \\ ${ }^{\#}$ Research Center of Waterproofing Technology in Institute of Construction Technology, \\ Seoul National University of Science \& Technology, Seoul 139-743, Korea. *E-mail: housedoctor@seoultech.ac.kr \\ Received March 28, 2014, Accepted June 13, 2014
}

\begin{abstract}
$\mathrm{Mn}_{3} \mathrm{O}_{4} /$ multi-walled carbon nanotube (MWCNT) composites are prepared by chemically synthesizing $\mathrm{Mn}_{3} \mathrm{O}_{4}$ nanoparticles on a MWCNT film at room temperature. Structural and morphological characterization has been carried out using X-ray diffraction (XRD) and scanning and transmission electron microscopies (SEM and TEM). These reveal that polycrystalline $\mathrm{Mn}_{3} \mathrm{O}_{4}$ nanoparticles, with sizes of about 10-20 nm, aggregate to form larger nanoparticles $(50-200 \mathrm{~nm})$, and the $\mathrm{Mn}_{3} \mathrm{O}_{4}$ nanoparticles are attached inhomogeneously on MWCNTs. The electrochemical behavior of the composites is analyzed by cyclic voltammetry experiment. $\mathrm{The} \mathrm{Mn}_{3} \mathrm{O}_{4} /$ MWCNT composite exhibits a specific capacitance of $257 \mathrm{Fg}^{-1}$ at a scan rate of $5 \mathrm{mVs}^{-1}$, which is about 3.5 times higher than that of the pure $\mathrm{Mn}_{3} \mathrm{O}_{4}$. Cycle-life tests show that the specific capacitance of the $\mathrm{Mn}_{3} \mathrm{O}_{4} /$ MWCNT composite is stable up to 1000 cycles with about $85 \%$ capacitance retention, which is better than the pure $\mathrm{Mn}_{3} \mathrm{O}_{4}$ electrode. The improved supercapacitive performance of the $\mathrm{Mn}_{3} \mathrm{O}_{4} / \mathrm{MWCNT}$ composite electrode can be attributed to the synergistic effects of the $\mathrm{Mn}_{3} \mathrm{O}_{4}$ nanoparticles and the MWCNTs, which arises not only from the combination of pseudocapacitance from $\mathrm{Mn}_{3} \mathrm{O}_{4}$ nanoparticles and electric double layer capacitance from the MWCNTs but also from the increased surface area, pore volume and conducting property of the MWCNT network.
\end{abstract}

Key Words : Carbon nanotubes, Chemical synthesis, Composite materials, Manganese oxides, Supercapacitor

\section{Introduction}

Supercapacitors have attracted much attention because of their unique capability as an energy storing device which can overcome the drawbacks of conventional capacitors and batteries. Supercapacitors not only exhibit fast charging/ discharging time, superior cycling life, and high reliability but also they can provide higher energy density than conventional capacitors and higher power density than batteries. ${ }^{1-3}$ Owing to the role of supercapacitors, which may bridge the gap between conventional capacitors and batteries, they have been utilized in a wide range of applications such as electric vehicles, electronic appliances, digital communication devices, and mobile phones. Carbon materials, transition metal oxides and conducting polymers have been explored as potential electrode materials used in supercapacitors. ${ }^{4-7}$ Among various transition metal oxides, ruthenium oxide is one of the most promising pseudocapacitor electrode materials because of its superior electrochemical response. ${ }^{8}$ However, despite the superior performance of ruthenium oxide, it is still limited in its industrial supercapacitor applications due to its high cost. ${ }^{9}$ Hence, considerable effort is being devoted to developing inexpensive metal oxide electrode materials with excellent supercapacitive performance. Among various alternative materials investigated, manganese oxides have attracted tremendous interest because of their high theoretical specific capacitance, natural abundance, and environmentally-friendly nature..$^{10,11}$ Especially, hausmannite $\left(\mathrm{Mn}_{3} \mathrm{O}_{4}\right)$ is potentially interesting materials, because of its unique structural features combined with physicochemical properties, which are of great interest in energy fields. ${ }^{12}$ However, only a few studies have been done with $\mathrm{Mn}_{3} \mathrm{O}_{4}$, because of its low electrical conductivity limiting the performance of $\mathrm{Mn}_{3} \mathrm{O}_{4}$ such as capacitance. An increase in mass loading and film thickness of manganese oxide further deteriorates the capacitive performance. To compensate for the poor electrical conductivity and dense morphology of the manganese oxide film, a thin layer of manganese oxide is deposited on the surface of a highly conductive and porous structure with high surface area, which can provide excellent supercapacitive performance with high mass loading of manganese oxide. The porous structure may be a metal foam, carbon fabric, graphene, or carbon nanotube film. ${ }^{13-17}$ Recent efforts to integrate $\mathrm{Mn}_{3} \mathrm{O}_{4}$ with porous structures have mostly focused on depositing $\mathrm{Mn}_{3} \mathrm{O}_{4}$ thin layers onto carbon nanotube (CNT) network films. The porous structures in CNT network films may offer effective pathways for electrolyte diffusion, and the highly conductive CNT network can act as a charge transportation pathway. In addition, CNTs are mechanically strong and chemically stable. Various methods have been employed for depositing $\mathrm{Mn}_{3} \mathrm{O}_{4}$ layers onto CNT films, 
including successive ionic layer adsorption and reaction (SILAR), ${ }^{18}$ dip-casting, ${ }^{19}$ electrophoretic deposition ${ }^{20}$ and chemical deposition. ${ }^{21}$ The drawbacks of these methods are that they contain time-consuming multiple steps and hightemperature processes for the synthesis of $\mathrm{Mn}_{3} \mathrm{O}_{4}$. Therefore, more environmentally friendly, faster, and energy-efficient synthetic methods are of interest. The chemical deposition method is one of the simplest methods to deposit thin films of nanomaterials on various substrates and is a scalable technique that can be employed for large area deposition. In the chemical deposition method, the morphology and film thickness can be controlled by adjusting growth conditions such as temperature, $\mathrm{pH}$, concentration, and solution composition. The morphology and growth of thin films also depend on the topographical and chemical nature of the substrate. ${ }^{22-26}$

In the present work, we report a simple and cost-effective chemical method to grow $\mathrm{Mn}_{3} \mathrm{O}_{4}$ nanoparticles onto multiwalled carbon nanotube (MWCNT) network films at room temperature, and the $\mathrm{Mn}_{3} \mathrm{O}_{4} / \mathrm{MWCNT}$ composite film is further utilized as a supercapacitor electrode. The $\mathrm{Mn}_{3} \mathrm{O}_{4} /$ MWCNT composite films have been characterized by a variety of techniques, including X-ray diffraction (XRD), Brunauer-Emmett-Teller (BET) surface area measurement, field emission scanning electron microscopy (FESEM), transmission electron microscopy (TEM) and energy dispersive X-ray (EDX) analysis. The electrochemical properties of $\mathrm{Mn}_{3} \mathrm{O}_{4} / \mathrm{MWCNT}$ composite electrodes are examined by cyclic voltammetry measurement, and the results reveal significant improvement in supercapacitive performance compared to pure $\mathrm{Mn}_{3} \mathrm{O}_{4}$ electrode.

\section{Experimental}

Analytical grade chemicals of manganese (II) chloride tetrahydrate (99.999\%) and ammonium hydroxide solution $\left(28 \% \mathrm{NH}_{3}\right.$ in $\left.\mathrm{H}_{2} \mathrm{O}, \geq 99.99 \%\right)$ were purchased from SigmaAldrich and used without additional purification. The MWCNTs with $15-20 \mathrm{~nm}$ diameters and $95 \%$ purity were purchased from Iljin Nanotech, Korea. Surface functionalization of the MWCNTs and their thin film formation on stainless steel (SS) substrates were carried out as described in previous reports, ${ }^{27,28}$ and the $\mathrm{Mn}_{3} \mathrm{O}_{4}$ nanoparticles were deposited on the MWCNT-coated SS substrates by using a chemical deposition method. ${ }^{26}$ Briefly, an aqueous solution of $0.1 \mathrm{M}$ manganese chloride was prepared, and the $\mathrm{pH}$ of the solution was adjusted with ammonia solution to 8.5 , which was used as the precursor solution for the deposition of the $\mathrm{Mn}_{3} \mathrm{O}_{4}$ films. The MWCNT-coated SS substrates were immersed in this solution for $24 \mathrm{~h}$ at room temperature. During precipitation, heterogeneous reactions occurred, and deposition of $\mathrm{Mn}_{3} \mathrm{O}_{4}$ nanoparticles occurred on the substrate. The $\mathrm{Mn}_{3} \mathrm{O}_{4} / \mathrm{MWCNT} / \mathrm{SS}$ substrate was removed from the bath and washed with double distilled water, dried in air and then characterized. Similarly, the $\mathrm{Mn}_{3} \mathrm{O}_{4}$ film was deposited on an SS substrate for comparison. The weights of the samples were measured by taking the difference of the weights of a substrate before and after film deposition. The weight percentage of CNTs in the composite is $20 \%$, and the mass loading of the active material $\left(\mathrm{Mn}_{3} \mathrm{O}_{4} / \mathrm{MWCNT}\right.$ composite) used was $0.54 \mathrm{mg}$.

A crystallographic study was carried out using an X-ray diffractometer (Rigaku 2500) with $\mathrm{CuK} \alpha$ radiation $(\lambda=$ $1.5418 \AA$ ). The surface morphology of the $\mathrm{Mn}_{3} \mathrm{O}_{4}$ and $\mathrm{Mn}_{3} \mathrm{O}_{4} /$ MWCNT composite films were investigated by field emission scanning electron microscopy (FESEM, Hitachi S4800) and transmission electron microscopy (TEM, JEOL JEM-2100F) operated at $200 \mathrm{kV}$. Compositions of the films were determined by energy dispersive X-ray (EDX) analysis. The BrunauerEmmett-Teller (BET) specific surface areas were obtained from nitrogen adsorption/desorption isotherms recorded at $196^{\circ} \mathrm{C}$. The electrochemical measurements were carried out in a typical three-electrode experimental cell equipped with a working electrode, platinum counter electrode and $\mathrm{Ag} /$ $\mathrm{AgCl}$ reference electrode. All the supercapacitor characteristics were measured using $1 \mathrm{M}$ aqueous $\mathrm{Na}_{2} \mathrm{SO}_{4}$ solution as an electrolyte. Cyclic voltammetry (CV) measurement was performed using a CHI 660D electrochemical workstation ( $\mathrm{CH}$ instrument, USA) to determine the electrochemical properties. Electrochemical impedance spectroscopy (EIS) measurements were recorded at the open circuit potential in the frequency range of $0.1 \mathrm{~Hz}$ to $1 \mathrm{MHz}$.

\section{Results and Discussion}

Figure 1 presents XRD patterns of the $\mathrm{Mn}_{3} \mathrm{O}_{4} / \mathrm{MWCNT}$, $\mathrm{Mn}_{3} \mathrm{O}_{4}$, and MWCNT films on SS substrates. An XRD pattern of the SS substrate is also included in the figure for comparison. The $\mathrm{Mn}_{3} \mathrm{O}_{4} / \mathrm{MWCNT}$ and $\mathrm{Mn}_{3} \mathrm{O}_{4}$ films show peaks at $18.00^{\circ}(101), 28.88^{\circ}(112), 32.32^{\circ}(103), 36.09^{\circ}$ (211), $37.98^{\circ}(004)$, and $59.84^{\circ}$ (224). These peaks match well with the standard pattern of tetragonal $\mathrm{Mn}_{3} \mathrm{O}_{4}$ (JCPDS 24-0734) without any collateral peaks, indicating high purity of the $\mathrm{Mn}_{3} \mathrm{O}_{4}$. Note that the characteristic graphitic peak of the MWCNTs at $26.22^{\circ}(002)$ is observed in both the MWCNT and $\mathrm{Mn}_{3} \mathrm{O}_{4} / \mathrm{MWCNT}$ film, and some peaks result from the SS substrates because the XRD analysis was performed on a thin film on the substrate.

As seen in Figure 2(a), $\mathrm{Mn}_{3} \mathrm{O}_{4}$ nanoparticles with diameters of 50 to $200 \mathrm{~nm}$ are deposited on SS substrate by the chemical deposition method. A high magnification image (Fig. 2(b)) further reveals a rough surface of individual nanoparticles. Figures 2(c) and 2(d) exhibit FESEM images of the $\mathrm{Mn}_{3} \mathrm{O}_{4} / \mathrm{MWCNT}$ films. As can be seen from the figures, the $\mathrm{Mn}_{3} \mathrm{O}_{4} / \mathrm{MWCNT}$ forms a highly porous threedimensional network film with $\mathrm{Mn}_{3} \mathrm{O}_{4}$ nanoparticles. This porous network strucutre provides a large amount of surface area and facilitates ion diffusion of electrolyte, and the electrically conductive MWCNT network frame enhances the charge transfer rate, which are beneficial for supercapacitive performance. The Brunauer-Emmett-Teller (BET) specific surface area measurements show that the surface area of the $\mathrm{Mn}_{3} \mathrm{O}_{4} / \mathrm{MWCNT}$ is $103 \mathrm{~m}^{2} \mathrm{~g}^{-1}$, which is much larger than the value of $38 \mathrm{~m}^{2} \mathrm{~g}^{-1}$ for pure $\mathrm{Mn}_{3} \mathrm{O}_{4}$. In addition, 


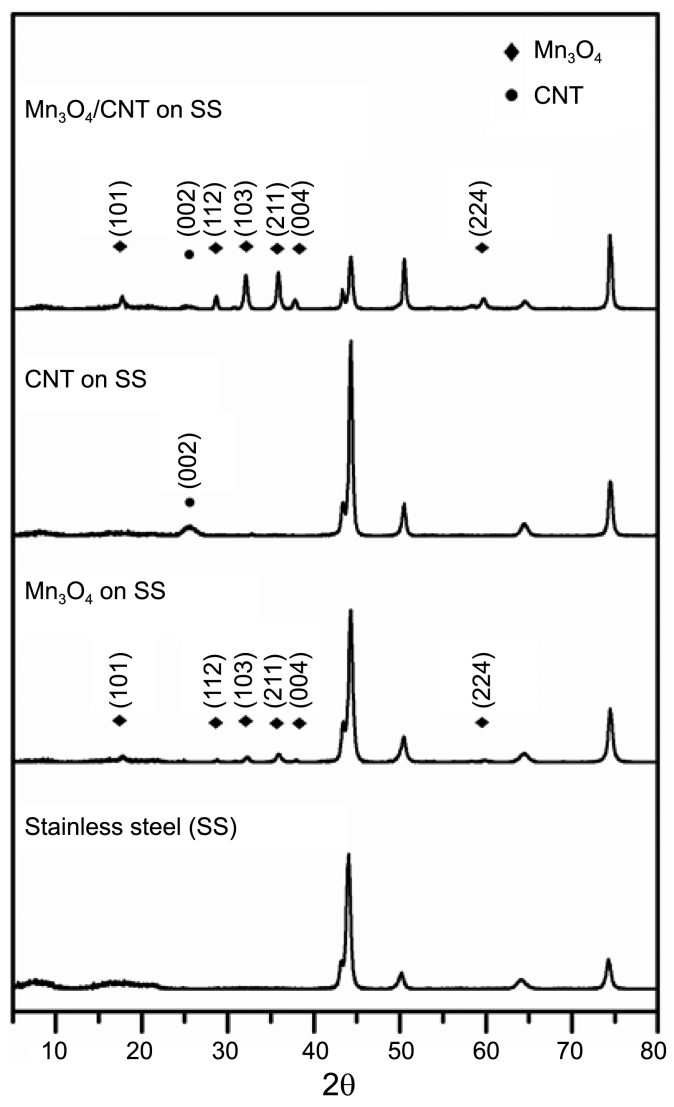

Figure 1. X-ray diffraction patterns of a stainless steel substrate, $\mathrm{Mn}_{3} \mathrm{O}_{4}, \mathrm{MWCNT}$, and $\mathrm{Mn}_{3} \mathrm{O}_{4} / \mathrm{MWCNT}$ samples.

the total pore volume of $\mathrm{Mn}_{3} \mathrm{O}_{4}$ and $\mathrm{Mn}_{3} \mathrm{O}_{4} / \mathrm{MWCNT}$ are 0.204 and $0.682 \mathrm{~cm}^{3} \mathrm{~g}^{-1}$, respectively. Therefore, $\mathrm{Mn}_{3} \mathrm{O}_{4} /$ MWCNT is expected to exhibit superior electrochemical properties than the pure $\mathrm{Mn}_{3} \mathrm{O}_{4}$.

TEM was used to further investigate structural and crystalline characteristics of the $\mathrm{Mn}_{3} \mathrm{O}_{4} / \mathrm{MWCNT}$ films. Figure 3 exhibits TEM images of the $\mathrm{Mn}_{3} \mathrm{O}_{4} / \mathrm{MWCNT}$ films. As seen in Figure 3(a), $\mathrm{Mn}_{3} \mathrm{O}_{4}$ nanoparticles, with sizes of about 10$20 \mathrm{~nm}$, aggregate and form larger nanoparticles with sizes about 50-200 nm. The $\mathrm{Mn}_{3} \mathrm{O}_{4}$ nanoparticles are attached
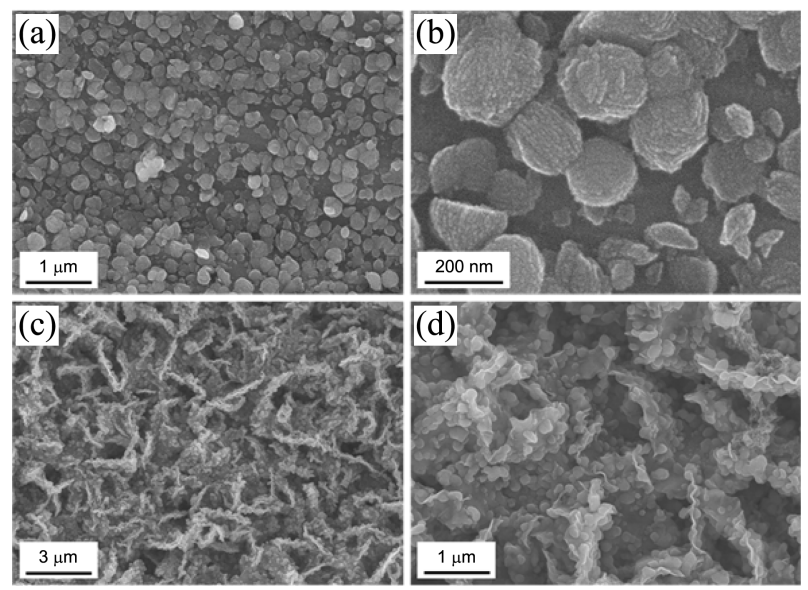

Figure 2. FESEM images of $\mathrm{Mn}_{3} \mathrm{O}_{4}$ (a and b) and $\mathrm{Mn}_{3} \mathrm{O}_{4} / \mathrm{MWCNT}$ (c and d) on stainless steel substrates.

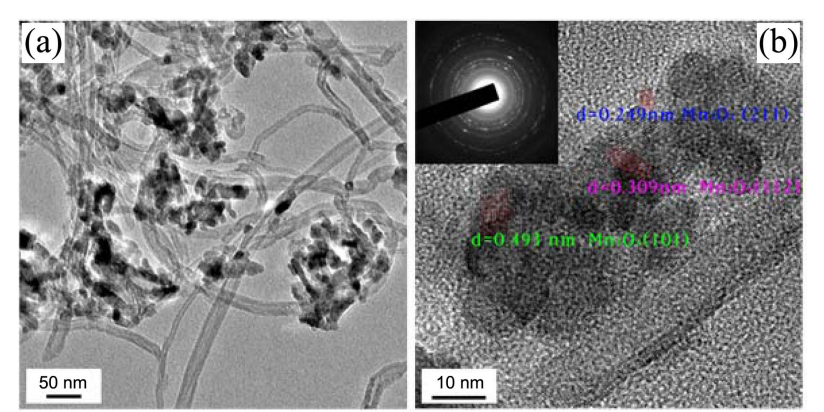

Figure 3. TEM images of $\mathrm{Mn}_{3} \mathrm{O}_{4} / \mathrm{MWCNT}$ at low (a) and high (b) magnifications. The inset shows the selected area electron diffraction (SAED) pattern.

inhomogeneously on the MWCNTs. High resolution TEM (Fig. 3(b)) shows the nanoparticles have aligned lattice fringes and measured interfringe distances of $0.493,0.309$ and $0.249 \mathrm{~nm}$, corresponding to (101), (112) and (211) dspacing of tetragonal $\mathrm{Mn}_{3} \mathrm{O}_{4}$ atomic plane orientation, respectively. For further analysis of crystalline structure of manganese oxide nanoparticles, the selected area electron diffraction (SAED) was conducted, and the SAED pattern is shown in Figure 3(b) (inset). The diffuse, spotty bright electron diffraction rings indicate a nanocrystalline nature of the $\mathrm{Mn}_{3} \mathrm{O}_{4}$ particles. Most of the rings are contributed by the characteristic crystal planes of $\mathrm{Mn}_{3} \mathrm{O}_{4}$, which is consistent with the XRD results. The composition of the $\mathrm{Mn}_{3} \mathrm{O}_{4} /$ MWCNT sample was determined by EDX (data not shown here). Only carbon, oxygen, manganese, and copper (from the $\mathrm{Cu}$ grid) peaks were detected, suggesting the formation of $\mathrm{Mn}_{3} \mathrm{O}_{4} / \mathrm{MWCNT}$ composite.

Cyclic voltammetry (CV) was employed to investigate electrochemical properties of the $\mathrm{Mn}_{3} \mathrm{O}_{4}$ and $\mathrm{Mn}_{3} \mathrm{O}_{4} / \mathrm{MWCNT}$ electrodes. Figure 4(a) shows the $\mathrm{CV}$ curves of $\mathrm{Mn}_{3} \mathrm{O}_{4}$ and $\mathrm{Mn}_{3} \mathrm{O}_{4} / \mathrm{MWCNT}$ electrodes, which were measured at a scan rate of $50 \mathrm{mVs}^{-1}$ in $1 \mathrm{M} \mathrm{Na}_{2} \mathrm{SO}_{4}$ electrolyte within a potential window ranging from -0.1 to $+0.9 \mathrm{~V}(v s . \mathrm{Ag} / \mathrm{AgCl})$. As seen in the figure, the pure $\mathrm{Mn}_{3} \mathrm{O}_{4}$ and $\mathrm{Mn}_{3} \mathrm{O}_{4} / \mathrm{MWCNT}$ electrodes both show the rectangular-like $\mathrm{CV}$ curves with no obvious redox peaks, which is the typical capacitive behavior of a manganese oxide electrode. The $\mathrm{Mn}_{3} \mathrm{O}_{4} / \mathrm{MWCNT}$ electrode exhibits larger capacitive current than pure $\mathrm{Mn}_{3} \mathrm{O}_{4}$, and the area of the $\mathrm{CV}$ curve for the $\mathrm{Mn}_{3} \mathrm{O}_{4} / \mathrm{MWCNT}$ is larger than that of pure $\mathrm{Mn}_{3} \mathrm{O}_{4}$, indicating better capacitive performance of the $\mathrm{Mn}_{3} \mathrm{O}_{4} / \mathrm{MWCNT}$ compared to the pure $\mathrm{Mn}_{3} \mathrm{O}_{4}$. The area under the $\mathrm{CV}$ curve can be used to estimate the specific capacitance of the electrode. The specific capacitance can be calculated from the $\mathrm{CV}$ curves using following equation:

$$
\mathrm{C}_{\mathrm{sp}}=\frac{1}{\mathrm{~ms}\left(\mathrm{~V}_{\mathrm{f}}-\mathrm{V}_{\mathrm{i}}\right)} \int_{\mathrm{V}_{\mathrm{i}}}^{\mathrm{V}_{\mathrm{f}}} \mathrm{I}(\mathrm{V}) \mathrm{dV}
$$

where $\mathrm{C}_{\mathrm{sp}}$ is the specific capacitance $\left(\mathrm{Fg}^{-1}\right)$, $\mathrm{m}$ is the mass of the active electrode material $(\mathrm{g}), \mathrm{s}$ is the potential scan rate $\left(\mathrm{mVs}^{-1}\right), \mathrm{V}_{\mathrm{f}}$ and $\mathrm{V}_{\mathrm{i}}$ are the integration limits of the voltammetric curve (V), and I(V) denotes the response current density $\left(\mathrm{Acm}^{-2}\right)$. From the $\mathrm{CV}$ curves, the specific capacitances 

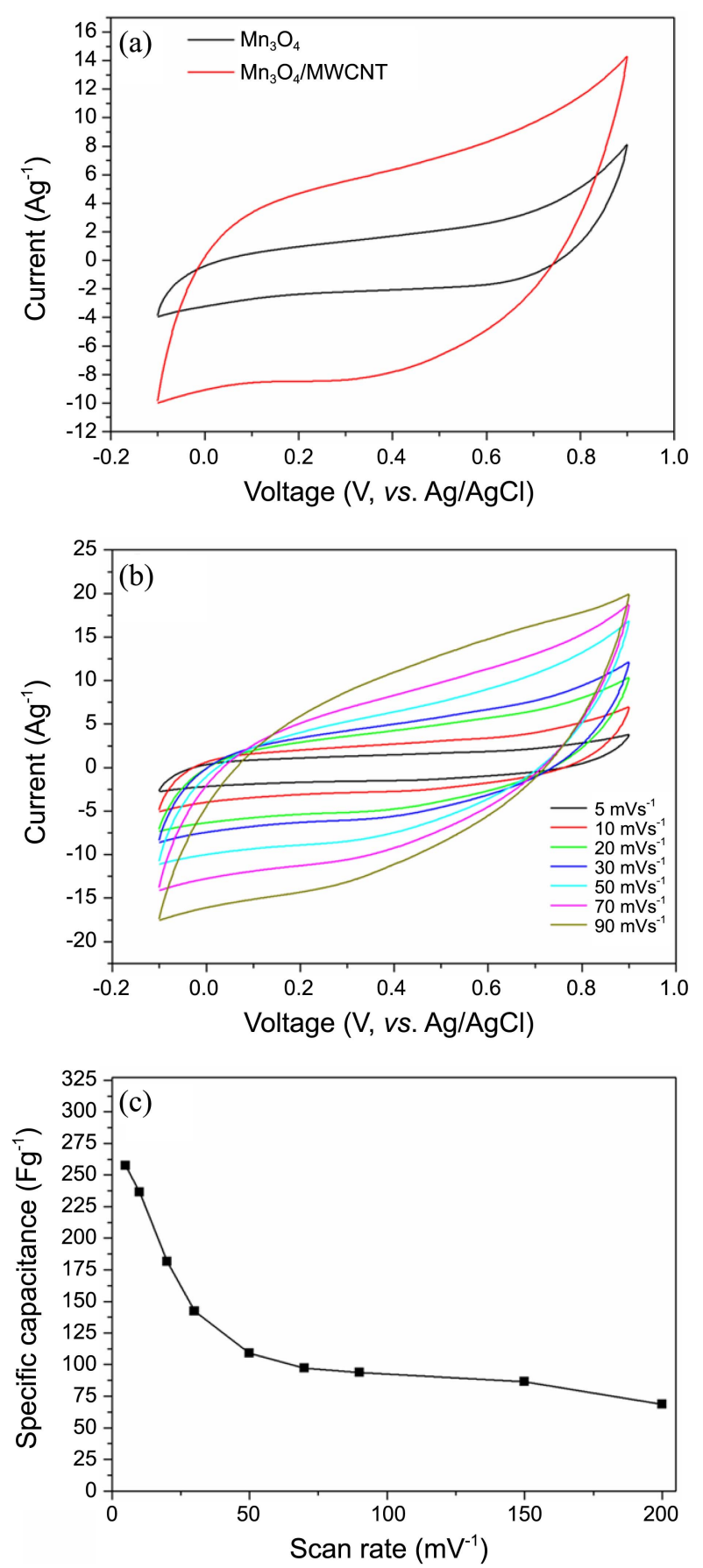

Figure 4. (a) Cyclic voltammograms of $\mathrm{Mn}_{3} \mathrm{O}_{4}$ and $\mathrm{Mn}_{3} \mathrm{O}_{4} /$ MWCNT electrodes at a scan rate of $50 \mathrm{mVs}^{-1}$. (b) Cyclic voltammograms of $\mathrm{Mn}_{3} \mathrm{O}_{4} / \mathrm{MWCNT}$ electrode at different scan rates. (c) Specific capacitances of $\mathrm{Mn}_{3} \mathrm{O}_{4} / \mathrm{MWCNT}$ electrode at different scan rates from -0.1 to $+0.9 \mathrm{~V}$ in $1 \mathrm{M} \mathrm{Na}_{2} \mathrm{SO}_{4}$.

of $\mathrm{Mn}_{3} \mathrm{O}_{4}$ and $\mathrm{Mn}_{3} \mathrm{O}_{4} / \mathrm{MWCNT}$ electrodes are 34.5 and $109.0 \mathrm{Fg}^{-1}$, respectively at a scan rate of $50 \mathrm{mVs}^{-1}$. The enhancement of the specific capacitance of the $\mathrm{Mn}_{3} \mathrm{O}_{4} /$ MWCNT electrode can be attributed to the higher surface area, conducting improvements by MWCNTs, and the combination of pseudocapacitive and EDLC properties, respectively, from the $\mathrm{Mn}_{3} \mathrm{O}_{4}$ nanoparticles and MWCNTs.

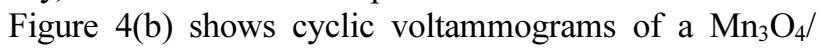
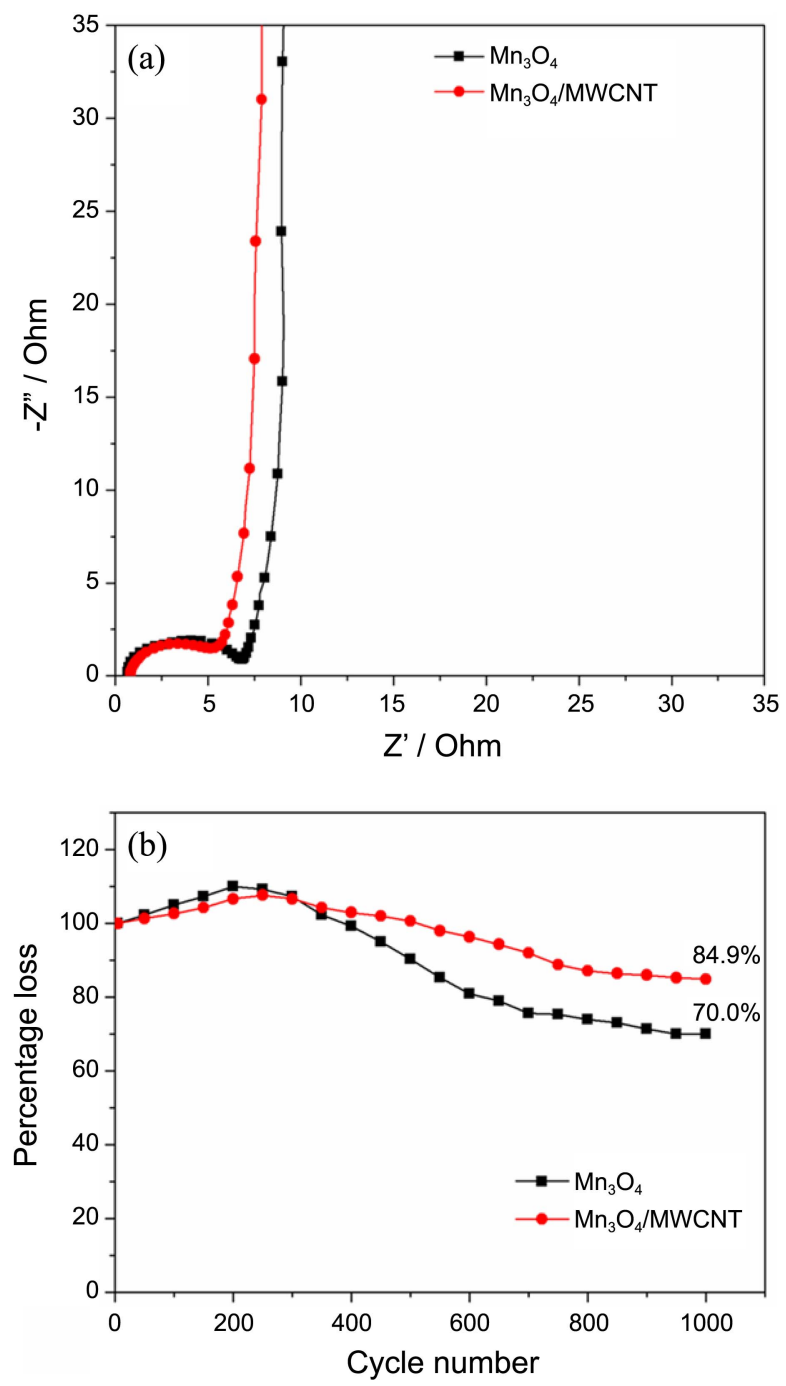

Figure 5. (a) Nyquist plots and (b) cycle stability test for $\mathrm{Mn}_{3} \mathrm{O}_{4}$ and $\mathrm{Mn}_{3} \mathrm{O}_{4} / \mathrm{MWCNT}$ electrodes.

MWCNT composite electrode at various scan rates. As can be seen in the figure, the shape of the CV curve does not significantly change with an increase in scan rate from 5 to $90 \mathrm{mVs}^{-1}$, further demonstrating excellent capacitive characteristics and fast response of the electrode. Figure 4(c) shows variations in the specific capacitance value of $\mathrm{Mn}_{3} \mathrm{O}_{4} /$ MWCNT composite as a function of scan rate. The specific capacitances of $\mathrm{Mn}_{3} \mathrm{O}_{4} / \mathrm{MWCNT}$ composite electrodes are 257, 236, 181, 142, 109, 97, 93, 86, and $68 \mathrm{Fg}^{-1}$ at 5, 10, 20 , $30,50,70,90,150$, and $200 \mathrm{mVs}^{-1}$, respectively. As shown in the figure, the specific capacitance decreases as the scan rate increases, indicating that fewer active sites are utilized for charge storage at higher scan rates. At high scan rates, the accessibility of electrolyte ions to the inner region of the porous electrode materials can be limitted due to the slow diffusion of the ions within the pores of the electrode material. Therefore only the outer surface of the electrode can be utilized for the charging process, resulting in low specific capacitance. At a very slow scan rate, however, most of the active regions can be involved in the charging process, 
resulting in high specific capacitance.

Figure 5(a) displays the Nyquist plots of the $\mathrm{Mn}_{3} \mathrm{O}_{4}$ and $\mathrm{Mn}_{3} \mathrm{O}_{4} / \mathrm{MWCNT}$ electrode in the frequency range of $0.1 \mathrm{~Hz}-$ $1 \mathrm{MHz}$ at the open circuit potential. Both $\mathrm{Mn}_{3} \mathrm{O}_{4}$ and $\mathrm{Mn}_{3} \mathrm{O}_{4} /$ MWCNT electrodes similarly show an arc in the high frequency region and an inclined line in low frequency regions. Note that the charge transfer resistance $\left(\mathrm{R}_{\mathrm{ct}}\right)$ at the electrode/ electrolyte interface can be estimated from the diameter of the arc. A distinct difference between the two curves is that $\mathrm{R}_{\mathrm{ct}}$ of $\mathrm{Mn}_{3} \mathrm{O}_{4} / \mathrm{MWCNT}$ is smaller than that of $\mathrm{Mn}_{3} \mathrm{O}_{4}$, indicating that $\mathrm{Mn}_{3} \mathrm{O}_{4} / \mathrm{MWCNT}$ composite electrode has lower charge transfer resistance than pure $\mathrm{Mn}_{3} \mathrm{O}_{4}$ electrode. This result can be contributed to the enhanced electrical conductivity and reduced diffusion length of electrolyte ions in $\mathrm{Mn}_{3} \mathrm{O}_{4} / \mathrm{MWCNT}$ composite electrode.

The cycling performance is also important for electrochemical supercapacitor application. Figure 5(b) demonstrates the stability characteristics of $\mathrm{Mn}_{3} \mathrm{O}_{4}$ and $\mathrm{Mn}_{3} \mathrm{O}_{4} / \mathrm{MWCNT}$ electrodes as a function of cycle number obtained from the cyclic voltammetric study. It can be noticed that the specific capacitance gradually increases up to 250 cycles, which may be due to the activation effect of electrochemical cycling. ${ }^{29,30}$ After 1,000 cycles, $\mathrm{Mn}_{3} \mathrm{O}_{4} / \mathrm{MWCNT}$ electrode can retain $85 \%$ of the initial capacity, but pure $\mathrm{Mn}_{3} \mathrm{O}_{4}$ retains only $70 \%$. This enhancement in cycling stability can be attributed to porous structure of $\mathrm{Mn}_{3} \mathrm{O}_{4} / \mathrm{MWCNT}$ in which the $\mathrm{Mn}_{3} \mathrm{O}_{4}$ nanoparticles are dispersed in the 3D MWCNTs network. Such structure can provide more space in the electrode and greater accessibility of the electrolyte ions to the available reactive sites, reducing degradation of the electrochemical performance in cyclic redox reaction.

\section{Conclusion}

A simple and cost-effective approach has been developed to fabricate $\mathrm{Mn}_{3} \mathrm{O}_{4} / \mathrm{MWCNT}$ nanocomposites at room temperature. Crystalline $\mathrm{Mn}_{3} \mathrm{O}_{4}$ nanoparticles with 50-200 $\mathrm{nm}$ in size are distributed in the MWCNT network. The resulting $\mathrm{Mn}_{3} \mathrm{O}_{4} / \mathrm{MWCNT}$ composite electrode achieves a large specific capacitance of $257 \mathrm{Fg}^{-1}$ at a scan rate of 5 $\mathrm{mVsec}^{-1}$, which is 3.5 times greater than that of a pure $\mathrm{Mn}_{3} \mathrm{O}_{4}$ electrode. In the $\mathrm{Mn}_{3} \mathrm{O}_{4} / \mathrm{MWCNT}$ composite, the MWCNT 3D network can not only provide electrical and ionic conducting channels in an electrolyte but also high surface area for the growth of $\mathrm{Mn}_{3} \mathrm{O}_{4}$ nanoparticles. Accordingly, the $\mathrm{Mn}_{3} \mathrm{O}_{4} / \mathrm{MWNT}$ composite electrode can exhibit higher specific capacitance, lower charge transfer resistance and better cycling stability compared with the pure $\mathrm{Mn}_{3} \mathrm{O}_{4}$ electrode. These improvements result from the highly accessible specific surface area, reduced diffusion length of ions, and enhanced electrical conductivity. This work demonstrates a design for a high performance supercapacitor electrode material by synthesizing metal oxide/CNT nanocomposites by a facile and low-temperature preparation process.
Acknowledgments. This research was supported by a grant from the Technology Development Program for Strategic Core Materials funded by the Ministry of Trade, Industry \& Energy (10047758) and grants from Basic Science Research Program through the National Research Foundation of Korea (NRF) funded by the Ministry of Education (2012R1A6A1029029 and 2012R1A2A2A01013080), Republic of Korea.

\section{References}

1. Simon, P.; Gogotsi, Y. Nature Mater. 2008, 7, 845.

2. Conway, B. E. Electrochemical Supercapacitors, Scientific Fundamentals and Technological Applications; Kluwer Academic/ Plenum Publishers: New York, USA, 1997; p 15.

3. Jayalakshmi, M.; Balasubramanian, K. Int. J. Electrochem. Sci. 2008, 3, 1196.

4. Pan, H.; Li, J.; Feng, Y. P. Nanoscale Res. Lett. 2010, 5, 654.

5. Zhang, L. L.; Xhao, X. S. Chem. Soc. Rev. 2009, 38, 2520.

6. Wang, G.; Zhang, L.; Zhang, J. Chem. Soc. Rev. 2012, 41, 797.

7. Snook, G. A.; Kao, P.; Best, A. S. J. Power Sources 2011, 196, 1.

8. Hu, C. C.; Chen, W. C.; Chang, K. H. J. Electrochem. Soc. 2004, 151, A281.

9. Wu, Z. S.; Wang, D. W.; Ren, W.; Zhao, J.; Zhou, G.; Li, F.; Cheng, H. M. Adv. Funct. Mater. 2010, 20, 3595.

10. Wei, W.; Cui, X.; Chen, W.; Ivey, D. G. Chem. Soc. Rev. 2011, 40, 1697.

11. Zhang, S. W.; Chen, G. Z. Energy Mater. 2008, 3, 186.

12. Wang, D.; Yuqi, Y.; Wang, Q.; Wang, T. Eur. J. Chem. 2012, 4, 628.

13. Lee, J. W.; Hall, A. S.; Kim, J.-D.; Mallouk, T. E. Chem. Mater. 2012, 24, 1158.

14. Li, D.; Meng, F.; Yan, X.; Yang, L.; Heng, H.; Zhu, Y. Nanoscale Res. Lett. 2013, 8, 535.

15. Li, Z.; Lin, N.; Wang, X.; Wang, C.; Qi, Y.; Yin, L. J. Mater. Chem. 2012, 22, 16640.

16. Jiang, L.; Fan, Z. Nanoscale 2012, 6, 1922.

17. Wang, T.; Peng, Z.; Wang, Y.; Tong, J.; Zheng, G. Sci. Rep. 2013, 3, 2693 .

18. Dubal, D. P.; Holze, R. New J. Chem. 2013, 37, 403.

19. Cui, X.; Hu, F.; Wei, W.; Chen, W. Carbon 2011, 49, 1225.

20. An, G.; Yu, P.; Xiao, M.; Liu, Z.; Miao, Z.; Ding, K.; Mao, L. Nanotechnology 2008, 19, 275709.

21. Chen, C. Y.; Chien, T. C.; Lin, C. K.; Wang, S. C. Diam. Relat. Mater. 2009, 18, 482.

22. Dubal, D. P.; Dhawale, D. S.; Salunkhe, R. R.; Fulari, V. J.; Lokhande, C. D. J. Alloys Compd. 2010, 497, 166.

23. Dubal, D. P.; Dhawale, D. S.; Salunkhe, R. R.; Pawar, S. M.; Fulari, V. J.; Lokhande, C. D. J. Alloys Compd. 2009, 484, 218.

24. Salunkhe, R. R.; Jang, K.; Yu, H.; Yu, S.; Ganesh, T.; Han, S. H.; Ahn, H. J. Alloys Compd. 2011, 509, 6677.

25. Salunkhe, R. R.; Jang, K.; Lee, S. W.; Ahn, H. RSC Advances 2012, 2, 3190.

26. Salunkhe, R. R.; Jang, K.; Lee, S. W.; Yu, S.; Ahn, H. J. Mater. Chem. 2012, 22, 21630.

27. Osorio, A. G.; Silveria, I. C. L.; Bueno, V. L.; Bergmann, C. P. Appl. Surf. Sci. 2008, 255, 2485.

28. Xu, H. Y.; Xu, S. L.; Wang, H.; Yan, H. J. Electrochem. Soc. 2005, 152, C803.

29. Tianyu, W.; Zheng, P.; Yuhang, W.; Jing, T.; Gengfeng, Z. Sci. Rep. 2013, 3, 2693.

30. Xiong, Z.; Xianzhong, S.; Haitao, Z.; Dacheng, Z.; Yanwei, M. Electrochim. Acta 2013, 87, 637. 